educed to a mere sac; the left kidney was of normal size, but presented signs of chronic interstitial nephritis, on which acute inflammation and miliary abscesses had recently supervened. The other organs were normal, there being no marked hypertrophy of the heart. In the pelvis and in the right iliac region were several cancerous $1 y m p h$ glands.

CASE 3. Cancer of the corpus nith dixsemination in the peritoneum that simulated cirrhosis of the liver.-An exceedingly intemperate woman was under the care of Constantin 3 with ascites and other symptoms of cirrhosis of the liver. The urine was loaded with urates. No indications of pelvic disease were noticed during life. At the necropsy the body of the uterus was found to be extensively affected with cancer, the cervix being but slightly diseased. There was extensive cancerous dissemination throughout the pelvic and abdominal peritoneum and in the pelvic and provertebral lymph glands.

Preston.

\section{CASE OF ACUTE ASCENDING MYELITIS COMPLICATING MEASLES.}

BY W. A. ELLIS O N, M.A., M.D. OXON.,

SORGEON-A POTHECARY TO HER MAJESTY'S HOLSEHOLD AT' WINDSOR; SURGEON TO THE WINDSOR ROYAL INETRMARY.

A scHOOLBOY aged fourteen years, of nervous and somewhat morbid temperament, was attacked with measles on March 30th, having been during the day in school and, presumably, in his usual health. Next day the rash came well out all over his body, and during the succeeding night he had a sharp attack of diarrhoea and vomiting, which subsided next morning, April 1st. The patient exhibited all the usual signs of a well-marked typical case of measles; the temperature had been up to $104^{\circ} \mathrm{F}$, but fell below this during the day, On the 2nd the symptoms declined; the boy reported himself as feeling comfortable except for pain in his back, and chatted with his parents. The evening temperature was $99^{\circ}$. On the $3 r d$ the temperature was normal. The patient informed his mother that he had passed no urine since the previous evening, and though this did not seem a very unusual or remarkable circumstance he was evidently troubled in his mind about it; later in the day he complained of vague pain about his body and legs and declared his conviction that he was going to have influenza; in the afternoon though the urine was still retained the bladder was by no means distended. In the evening a dose of castor oil was given in the hope that the urine might be passed when the bowels acted; the oil did its duty in due course but little or no urine was passed; and at 11 P.M. a catheter was used and about half a pint of urine was drawn off. The boy bore the catheterisation with what appeared to be extraordinary equanimity and afterwards said he was fairly comfortable, but had "sort of influenza pains" in his toes and legs. The temperature was $103.4^{\circ}$ The patient spent a restless night, and on the 4 th at $9.30 \mathrm{~A} . \mathrm{M}$. he was found to have complete paraplegia with absolute ancesthesia from his toes up to his axillæ, where there was very slight sensation. Thoracic movement was much impaired, the superficial reflexes about the thorax and the abdomen were very slight, and the reflexes of the lower extremities were entirely absent. The temperature was $103 \cdot 4^{\circ}$ but by 11.30 A.M. it had risen to $104.4^{\circ}$ and the patient was drowsy and complained of pain in the hands and the forearms, and the grasp of both hands was decidedly weak. The catheter was passed. At 2 P.M. the temperature was over $105^{\circ}$ and motions had been passed unconscionsly. At 5 P.M. he was drowsy but conscious; the speech was not affected; the temperature fell slightly, but at 8 P.M. it had risen to $107^{\circ}$ and the patient was almost unconscious. There was absolutely no movement of the thorax; the respirations were 32 and entirely abdominal. At 11 P.M. they numbered 46 and coma had supervened. At 2 A.M. on the 5th the respirations were 50 . the temperature was $107 \cdot 5^{\circ}$, and the patient was still able to swallow. At $5.20 \mathrm{~A}$ M. the temperature taken immediately after death was $109 \cdot 2^{\circ}$.

Remaris -. This case occurred during an extensive epidemic of a decidedly virulent type of measles. In many instances

3 Nourelles Archives d'Otstétrique et de Gynécolǫ́ie, July, 1832. the rash was very slow in making its complete appearance ; in one case at least an entire week intervened between the first appearance of "mottling" and the full development of the rash. As a rule the rash was unusually dark and in some cases it approached a hæmorrhagic type. As to the boy's constitution and general health nothing remarkable seems to have been noticed; but his father informed me that his memory was extremely defective, that he was therefore very "backward" and, consequently, at times despondent and hopeless. The rare occurrence of this fatal disease as a sequel to the exanthemata may perhaps render these short notes of interest to the profession. Eton.

\section{Clinital 繁ntes:}

\section{MEDICAL, SURGICAL, OBSTETRICAL, AND THERAPEUTICAL.}

\section{A CASE OF ABSENCE OF THE THYMUS GLAND IN AN INFANT.}

By Alfred Clark, L.R.C.P. \& S. Edin,, L.F.P.S. GlasG.

ON Aug. 4th, 1896, a male child aged eight months was brought to me by his mother on account of persistent swelling of the hands and feet. The family history was unimportant and the parents were both healthy. The previous history of the case was as follows. At birth the child was apparently well nourished and healthy and continued to be so until six months old in spite of being fed from a dirty bottle and being otherwise neglected. About the sixth month the mother noticed a slight swelling and coldness of the hands and feet, and on that account took the patient to a medical man. The swelling, however, increased and spread to the legs, and on Aug. 4th the case came under my care. The child was then considerably swollen, and "waxy"-or, rather, "tallowy"-in complexion; the heart and lung sounds were normal. There was no cyanosis. The fundi oculorum were normal. The bowels were relaxed; the motions were greenish and offensive. The urine (1016) was acid; there was no albumin. There was slight excess of urates. The quantity of urine passed was not notably deficient. The swelling gradually increased and spread in spite of diuretic and tonic treatment until the eyes were almost closed and the hands, arms, feet, and legs were so distended with fluid as to feel like a firmly-stuffed cushion. On Sept. 1st I noticed two symmetrical ecchymoses, one on the inner side of each supra-clavicular fossa and about the size of a florin. The temperature remained normal and the pulse and respiration grew weaker as death approached, but were in no way remarkable. On Sept. 5th the child died.

Necropsy. - At the necropsy, made twelve hours later, I found the right kidney healthy; the left was about twice the size of the right, and its pelvis and ureter were dilated, the latter to the size of the little finger and the former to contain about two fluid drachms. There was no communication with the bladder on the left side, although the ureter was pervious as far as that organ. The thymus gland was completely absent, the upper part of the anterior mediastinum being empty and the pleurx in apposition. There was no fibrous tissue to mark the position of the absent organ.

Remarks. - So far as I know this condition of things is quite unique as regards the absence of the thymus gland, and is interesting as proving that it is compatible with fair health and normal development-at all events, for the first six months of life. The symmetrical ecchymoses arising without apparent cause harmonise with the reccrded connexion between this gland and hæmophilia. I think that the renal abnormality only contributed in a subsidiary degree to the fatal result, as the hydronephrosis was slight and the right kidney quite healtby and apparently adequate for the necessities of the body, for no uræmic symptoms were present and the urine passed was not deficient. There were no symptoms of acromegaly. The digestive functions improved under treatmerit and the appetite remained good to the last.

Leicester. 